\title{
The Reinforcing Effect of Sugar Palm Fiber on PP
}

\author{
Kenneth Genesius Han ${ }^{1, a,}$, Juliana Anggono ${ }^{1, b}$, Peter Jonathan ${ }^{1, c}$ \\ ${ }^{1}$ Mechanical Engineering Department, Petra Christian University, Jalan Siwalankerto 121-131, Surabaya 60236, Indonesia \\ 'm24 415053@alumni.petra.ac.id, 'julianaadpetra.ac.id, "peter.jonathan@petra.ac.id
}

\begin{abstract}
Natural fibers have the ability to reinforce polymeric materials. In this work, sugar palm fibers were added as a reinforcement agent to a polypropylene (PP) matrix to form biocomposites. Flexural strength measurement in accordance with ASTM D790-17 was carried out on PP composites with the sugar palm fiber content changed from 0 to $30 \mathrm{wt} . \%$ in $5 \mathrm{wt} . \%$ steps. The flexural strength data show a composition dependence on the fiber content with a maximum (52.09 MPa) obtained in $15 \mathrm{wt} . \%$ fibers. Sugarcane bagasse-PP composite together with wood board composite and neat PP as existing materials by the automotive industry were used as reference materials in the study. These sugar palm fiber-PP composites offer lower density in comparison with wood board composites and PP. The area density of the composites is in the range of $1285-1635 \mathrm{~g} / \mathrm{m}^{2}$ for the composition studied while PP and wood board have area densities of $1466 \mathrm{~g} / \mathrm{m}^{2}$ and $1700 \mathrm{~g} / \mathrm{m}^{2}$ respectively.
\end{abstract}

Keywords: Composites, natural fibers, flexural strength, polymer, area density.

\section{Introduction}

The automotive industries are urged to address challenges concerning users and the environment. The fact shows that almost a quarter of all greenhouse gas (GHG) emissions are from road transport. Therefore the original equipment manufacturers (OEMs) need to go through an important development phase to solve of the biggest tasks in reducing the weight of automobiles to reduce fuel consumption.

In the US, CAFE (Corporate Average Fuel Economy) standards require automakers to deliver a fleet average of at least $54.5 \mathrm{mpg}$ by 2025 [1]. Despite of that, increasing customers toward a green lifestyle, along with energy security issues, are expected to push the demand for alternate materials for automobiles. According to Assembly magazine's "State of the Profession Survey that since 2017, the attention in using lightweight materials has risen by 11 percentage points." [2] A lighter object requires less energy to accelerate than a heavier one, or in other words that lightweight materials offer great potential for increasing vehicle efficiency.

In an annual survey sponsored by DuPont Automotive (Troy, MI) in response to the 2025 CAFE standard, it was reported that 49 percent of the respondents suggested that the lightweighting and use of lightweight structural materials will be the key enabler in realizing 2017-2025 CAFE standards [3]. The main routes to automotive lightweighting include parts consolidation, design optimization, and material substitution. The emphasis of this current work is on the search for an alternative material for a package tray application.

Polymeric materials have shown a promise to automakers in delivering lightweighting solutions. However, these materials are not without drawbacks regarding their strength and stiffness when they are used as structural parts. Natural fibers can offer a good reinforcement for polymers for structural application in the automotive industry, such as bumper, package tray, trunk panel, brake pads, and interior trim panel $[4,5]$.

There have been many studies focused on biocomposites in response to the increasing environmental concerns. Various natural fibers as side products or waste were employed as reinforcing agents for PP. They were sugarcane bagasse [6,7], wood flour [8, 9], and kenaf fibers [10]. The properties of composite material are influenced by the properties of its constituents, i.e. the properties of the fiber and the matrix, their chemical composition, the composite structure, and interfacial interactions between the fibers and the matrix [11]. Natural fibers have high moisture sensitivity, in which SPF is not an exception. This characteristic causes a huge restriction to their successful exploitation in manufacturing durable composites for outdoor applications (i.e. exterior automotive parts, flooring for outdoor uses).

The other concerns that are challenging in the use of biocomposites are the poor fiber-matrix adhesion. Most natural fibers are hydrophilic whereas polymeric matrices (i.e. thermoplastics/thermosets) are hydrophobic ("non-polar"). These particular drawbacks drew many research works focusing on the surface modification approach, such as alkali treatment and by using chemical "coupling" or "compatabilising" agents [12,13]. Accordingly, this present work aimed to explore the reinforcing potential of sugar palm fibers added to $\mathrm{PP}$ at various compositions in the range of 5 to $30 \mathrm{wt}$ \% fibers to study the effect of composition on composite properties. Sugar palm fibers (SPF) can be obtained from sugar palm trees (arenga pinnata) which are grown locally in Indonesia (Figure 1).
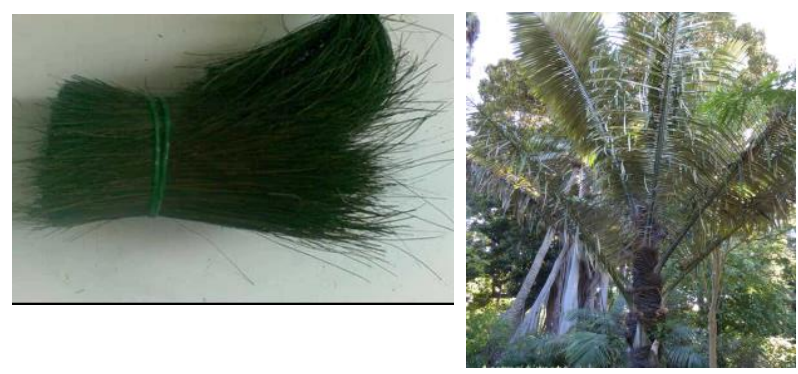

Figure 1. (a) SPF and (b) sugar palm tree (arenga pinnata) $[14,15]$ 


\section{Research Methods}

The SPF was obtained from a local seller in Sidoarjo, Indonesia. PP fibers were supplied by PT. Classic Prima Carpet Industries in Surabaya, Indonesia. Before both fibers were mixed manually, the first SPF was cut up to a length of $30 \mathrm{~mm}$ and neutralized with $70 \%$ ethanol for one hour. Afterward, they were dried up in the open air for 6 hours and moved to a Memmert oven at $100^{\circ} \mathrm{C}$ for 24 hours. Both PP and SPF were weighed to make up a 100-gram mixture with a composition range between 5 to $30 \mathrm{wt} \%$ SPF in 5 wt.\% steps. Table 1 provides the weight of each sample prepared for characterization. To ensure a homogeneous mixture of PP and SPF was obtained, both fibers were mixed manually in a smaller weight of $20 \mathrm{~g}$. To build up a panel specimen of $100 \mathrm{~g}$, five mixtures of well-mixed $20 \mathrm{~g}$ were prepared. Each of this $20 \mathrm{~g}$ mixture was then added up to a preform mold made from a pair of acrylic panels which was assembled vertically with a distance of $3 \mathrm{~mm}$ apart from one another. A green panel of 200x $100 \mathrm{~mm}$ with a thickness of $3 \mathrm{~mm}$ was obtained and to be ready for hot pressing.

Table 1. The composition and weight of the prepared samples

\begin{tabular}{cccc}
\hline Sample & \% weight ratio & \multicolumn{2}{c}{ Weight $(\mathrm{g})$} \\
\cline { 3 - 4 } & SPF/PP & SPF & PP \\
\hline $\mathrm{A}$ & $5 / 95$ & 5 & 95 \\
$\mathrm{~B}$ & $10 / 90$ & 10 & 90 \\
$\mathrm{C}$ & $15 / 85$ & 15 & 85 \\
$\mathrm{D}$ & $20 / 80$ & 20 & 80 \\
$\mathrm{E}$ & $25 / 75$ & 25 & 75 \\
$\mathrm{~F}$ & $30 / 70$ & 30 & 70 \\
\hline
\end{tabular}

Hot pressing was done in two steps. The first step was to make a preform in which the green panel was pressed with a pressure of $0,389 \mathrm{MPa}$ at a temperature of $150^{\circ} \mathrm{C}$ for 6 minutes. As the heating element was only provided in the lower mold, therefore, the panel needed to be turned over so that the unheated face could experience the heating from the lower mold. The procedure was repeated with similar pressure, temperature, and holding time. Following the first step, the second step of hot pressing was performed to the preform. Processing parameters were the same as the parameters in the first step except for the heating temperature that was increased to $190^{\circ} \mathrm{C}$. The hot pressed panels of various compositions were cut up to make specimens for flexural tests in accordance with ASTM D790-17. The flexural test (temperature $23^{\circ} \mathrm{C}$, humidity $57.4 \%$, speed $1.12 \mathrm{~mm} / \mathrm{min}$ ) was done using Shimadzu AG-X Plus $50 \mathrm{kN}$ at Center for Polymer Technology (Sentra Teknologi Polimer - BPPT), Serpong, Indonesia. Before testing, sample thickness and weight were measured to collect data of thickness and area density.

\section{Result and Discussion}

The results are first explained the effect of SPF reinforcement and hot pressing on the dimension and area density of the samples. The next discussion is with a similar effect on the flexural strength of the composites. Figure 2 shows the sample thickness measured as hot-pressed samples with SPF content varied in the range of $5 \mathrm{wt} . \%$ to $30 \mathrm{wt}$. \%.

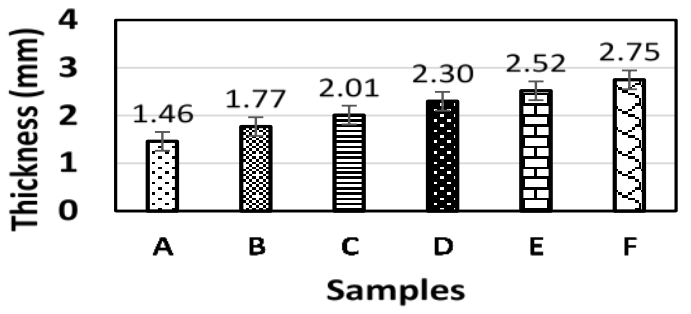

Figure 2. Sample thickness from various SPF content

It shows that the thickness displayed an increase with the larger content of SPF. This is true as the SPF is much stiffer (5 GPa) [16] than PP, therefore, its presence in a larger amount serves as the structural framework with an increased thickness of the composites when the area was maintained constant.

As lightweighting is one of the main considerations for automotive parts to achieve a fuel-saving car, therefore, area density is the parameter for a two-dimensional product to ascertain that the attribute can be compared with the specification required by the automotive industry. The reference specification used was obtained from PP and wood board composites as existing materials used by the industry.

Figure 3 provides the information on area density (reference thickness is $1.6 \mathrm{~mm}$ ) with the changes in SPF content in the composites. The area density shows a decrease with the larger amount of SPF and the values are quite promising as the SPF composites offer less area density compared to sugarcane bagasse-PP, neat PP, and two types of wood board of different compositions [17]. The lower density of SPF, i.e. $1.29 \mathrm{~g} / \mathrm{cm}^{3}[18]$ compared to the density of sugarcane bagasse $\left(1.29 \mathrm{~g} / \mathrm{cm}^{3}\right)$ [19] contributes to the lower area density of SPF-reinforced composites.

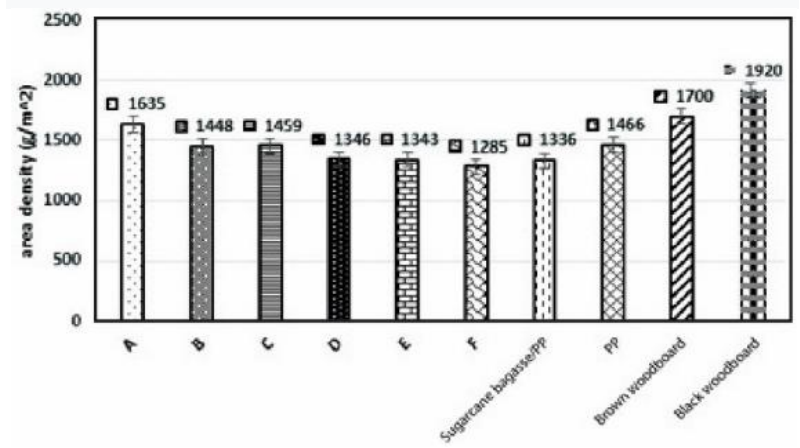

Figure 3. Dependence of the area density of PP/sugarcane bagasse fiber composites on composition, initial fiber dimensions, and hot pressing parameters.

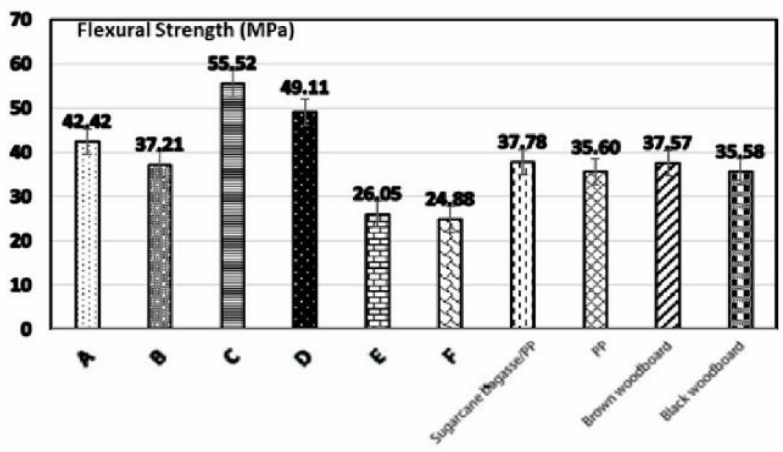

Figure 4. Composition dependence of the flexural strength of $\mathrm{PP} / \mathrm{SPF}$ composites. 


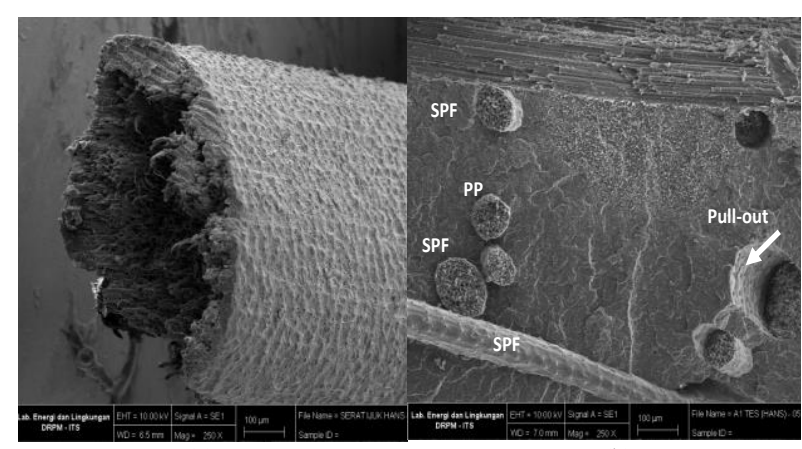

(a)

(b)

Figure 5. SEM micrographs a) neat SPF and b) crosssectional area of sample D

Flexural strength measurement was performed through a three-point bend test to evaluate the performance of SPF-PP composites as a response to the applied stress. The SPF is used as reinforcement for PP up to $20 \mathrm{wt}$ \% SPF increases the flexural strength considerably (Figure 4). Comparing to the neat PP, the increase in flexural strength of the SPF composite can be as large as $56 \%$ at the SPF content of 15 wt.\%. However, larger content of SPF, i.e. $20 \mathrm{wt} \%$, its flexural strength is still acceptable even beyond the required industrial specification and sugarcane bagasse-PP composites reported elsewhere [17]. Natural fibers are unable to provide uniform and consistent properties as they have a wide range of characteristics and cause the properties of the composites prepared from them can vary considerably. This results in the standard deviation obtained from flexural strength in the range of 5.19 to $5.83 \mathrm{MPa}$ for samples $\mathrm{F}$ and $\mathrm{C}$ respectively and 12.8 to $21.98 \mathrm{MPa}$ in the other samples. This large deviation in strength could come from the different characteristics of fibers (aspect ratio) as well as a structural formation during the processing of composites. The structural evaluation was studied using a scanning electron microscope (SEM) observing the SPF orientation, homogenous mixing with PP, and the presence of the voids due to air bubbles.

It is important to note that the SPF used in the study (Figure 5a) was given no treatment unlike the sugarcane bagasse used as the reference material. The tensile strength of SPF (ijuk) is 276.6 MPa and tensile modulus of $5 \mathrm{GPa}$ [16]. Bagasse has a tensile strength of 20-290 MPa and tensile modulus of 19.727.1 GPa [18]. The drop of flexural strength when more than 20 wt.\% SPF content was added might be caused by several possibilities, i.e. insufficient PP available to wet all SPF therefore those compositions provided weak interfacial adhesion of SPF and PP and/or other possibility was attributed to the presence of air bubbles in the composite, which serve as the weakest area for fracture $[16,17]$. Figure $5 b$ shows the SEM study of the fracture surface of sample D (a trial sample using $10 \mathrm{~mm} \mathrm{SPF}$ ) which shows information related to the reinforcement of SPFs. SEM micrograph shows the presence of SPFs was at different orientations in the PP matrix and weak interfacial adhesion between SPF and PP (unwetted SPF) was evident through fiber pull-out during deformation. Further investigation on the structural examination needs to be done to obtain an insight of the adhesion between the fibers and the matrix. This information can be useful to provide direction for the further work needed, as the addition of coupling agent and other treatment for SPF.

\section{Conclusion}

SPF provides a good reinforcing potential to PP and their composites can be used as the alternative material for automotive products. The flexural strength obtained at lower SPF content (no treatment) was considerably high compared to sugarcane-PP and wood board composites from the industry. The interfacial adhesion becomes poor as the SPF added more than $20 \mathrm{wt} . \%$ due to the wetting issue and the possible presence of air bubbles in the structure. A further investigation on the composition above $20 \mathrm{wt}$. \% needs to be carried out to analyze the adhesion between SPF and PP therefore a recommendation for improvement can be given.

\section{Acknowledgments}

The Ministry of Research, Technology, and Higher Education of the Republic of Indonesia for its research fund no: 002 / SP2H / LT / Mono / L7 / 2019 is greatly acknowledged. The authors would also like to thank PT. Classic Prima Carpet Industries for the supply of PP fibers.

\section{References}

[1] U.S. Environmental Protection Agency, Office of Transportation and Air Quality, "EPA and NHTSA Set Standards to Reduce Greenhouse Gases and Improve Fuel Economy for Model Years, 2017-2025 Cars and Light Trucks," (pdf file, 2012).

[2] https://www.prescouter.com/2020/01/automoti ve-lightweight-materials-composite/retrieved on 20 December 2020.

[3] https://www.dupont.de/news/WardsAuto-survey2017.html retrieved on 21 December 2020.

[4] Flowers, B., Automotive Applications for Polypropylene and Polypropylene Composites, in: H. Karian (Ed.), Handbook of Polypropylene and Polypropylene Composites, revised and expanded, CRC Press, Boca Raton, 2003, pp. 578-586.

[5] Pilla, S. and Lu, Y.C., Biocomposites Automotive Applications, SAE International, Pennsylvania, 2015.

[6] Anggono, J., Farkas, Á.E., Bartos, A., Móczó, J., Antoni, Purwaningsih, H., Pukánszky, B., Deformation and Failure of Sugarcane Bagasse Reinforced PP, Eur. Polym. J. 112 (2019), pp. 153-160.

[7] Bartos, A., Utomo, B. P., Kanyar, B., Anggono, J., Soetaredjo, F. E., Móczó, J. and Pukánszky, B., Reinforcement of Polypropylene with Alkali Treated Sugarcane Bagasse Fibers: Mechanism and Consequences, Composites Science and Technology 200 (2020) 108428.

[8] Dányádi, L., Móczó, J., Pukánszky, B., Effect of Various Surface Modifications of Wood Flour on the Properties of PP/Wood Composites, Compos. Part A Appl. Sci. Manuf. 41(2) (2010), pp. 199-206.

[9] Dányádi, L., Renner, K., Szabó, Z., Nagy, G., Móczó, J., Pukánszky, B., Wood Flour Filled PP Composites: Adhesion, Deformation, Failure, Polym. Adv. Technol. 17(11-12) (2006), pp. 967-974.

[10] W.J. Liu, L.T. Drzal, A.K. Mohanty, M. Misra, Influence of Processing Methods and Fiber Length on Physical Properties of Kenaf Fiber Reinforced Soy Based Biocomposites, Compos. B. Eng. 38(3) (2007), pp. 352359. 
[11] Faludi, G., Link, Z., Renner, K., Móczó, J., Pukánszky, B., Factors Determining the Performance of Thermoplastic Polymer/Wood Composites; the Limiting Role of Fiber Fracture, Mater. Des. 61 (2014), pp. 203-210.

[12] Koronis,G., Silva, A., Fontul, M., Green Composites: Are View of Adequate Materials for Automotive Applications, Compos Part B Eng (2013), 44 (1), pp. 120-127.

[13] Bartos, A., Utomo, B.P., Kanyar, B., Anggono, J., Soetaredjo, F.E., Móczó, J., and Pukánszky, B., Reinforcement of Polypropylene with Alkali-Treated Sugarcane Bagasse Fibers: Mechanism and Consequences, Compos. Sci. Tech. (2020), 200 (10) 108428.

[14] https://www.indonetwork.co.id/product/ijuk-bahan-sikatbrush-2565092 retrieved on 24 December 2020.

[15] https://ngoosen.fotki.com/arecaceae/arenga/arenga-pinnata-1.html retrieved on 24 December 2020.
[16] Sahari J, Sapuan SM, Ismarrubie ZN, Rahman MZA. Physio-chemical properties of different parts of sugar palm fibre. Fibers Text East Eur, 20 (2012), pp 23-26

[17] Anggono, J., Sugondo, S., Alim, R., Purwaningsih, H., and Wibawa, A., Performance and Evaluation of Low Cost Sugarcane Bagasse - Polypropylene Biocomposites as Candidate Material for Automotive Parcel Tray, Materials Science Forum, 923 (2018), pp 40-46.

[18] Razak, H.A. and Ferdiansyah, T., Toughness Characteristics of Arenga Pinnata Fibre Concrete, J. Nat Fibers 2 (2005), pp. 89-103.

[19] Rowell, R.M., Natural Fibres: Types and Properties in: Pickering, K.L, editor, Properties and Performance of Natural-Fibre Composites, Cambridge England: Woodhead Publishing Limited (2008), pp.3-66. 